\title{
Políticas públicas e a promoção da saúde por meio da leitura: ler + dá Saúde!
}

\begin{abstract}
Resumo: O objetivo deste artigo é realizar uma breve revisão do campo de estudos que articula as políticas públicas e a promoção da saúde por meio da leitura. O tema é a política pública para leitura e o objeto é o projeto Ler Dá + Saúde desenvolvido pelo Plano Nacional de Leitura de Portugal (PNL). Tem como objetivos específicos demonstrar a importância da literacia em leitura, discutir algumas das políticas públicas em Portugal, e destacar alguns aspectos do projeto Ler + Dá Saúde. Como metodologia, trata-se de um texto de revisão, e desse modo se constitui do tipo bibliográfica e documental. Utilizou-se dados do portal e sítios eletrônicos do PNL, a exemplo do Ler + Dá Saúde. Os resultados das observações e discussões com a literatura sobre o tema proposto permitiram concluir que o projeto tem se destacado como proposta social por ser uma política pública que tem visado a convergência da leitura, saúde e família, unindo às Tecnologias de Informação e Comunicação (TIC) e como proposta estratégica do programa PNL para fortalecer a letramento no país.
\end{abstract}

Palavras-chave: Políticas públicas da leitura. Plano Nacional de Leitura. Portugal. ProjetoLer + DáSaúde. PromoçãoemSaúde.

\section{Introdução}

O presente artigo tem como tema as políticas públicas de leitura. Apresenta como objetivo realizar uma breve revisão do campo de estudos que articula as políticas públicas e a promoção da saúde por meio da leitura. Especificamente objetiva demonstrar a importância do letramento ${ }^{1}$ em leitura, discutir algumas das políticas públicas em Portugal, e destacar alguns aspectos do projeto Ler + Dá Saúde.

É importante ressaltar que este artigo não tem a intenção de fornecer um estado da arte definitivo e categórico sobre o assunto, pois tal tarefa demandaria não apenas a ampliação do número de artigos, sites visitados, documentos, livros, compêndios a serem identificados e analisados, como também a inclusão de outras produções apresentadas em eventos como objetos de análise.

Contudo, não obstante o escopo reduzido do debate proposto, e considerando o número limitadode trabalhos que tratam sobre o objeto em destaque neste texto, acredita-se que este artigo seja capaz de apontar para algumas importantes direções no que tange aos estudos sobre as dimensões das políticas públicas voltadas para questões pedagógicas da literatura infantil e da promoção em saúde.
Barbara Coelho Neves Programa de Pós-Graduação em Educação

Universidade Federal da Bahia barbaran@ufba.br

Patrícia V. Nascimento D. Fernandes

Doutora em Ciência da Educação Universidade do Minho/Portugal. fernandes.patricinha@gmail.com

(1) Em Portugal usa-se literacia, termo que aborda o conceito que traduz a habilidade e capacidade de ler e compreender o conteúdo escrito nas diversas formas, incluindo as competências requeridas para tal em sociedade. Frente ao entendimento deste conceito, o termo em português brasileiro que se acha mais adequado, conforme as discussões tratadas neste texto, éo termo letramento. 
Desse modo, o artigo está dividido em cinco seções, a contar com esta introdução. A segunda seção trata da importância do letramento e leitura. Na terceira seção são abordadas as políticas públicas contemporâneas voltadas para leitura em Portugal, destacando o Plano Nacional de Leitura (PNL) e o seu portal eletrônico. Em seguida, na quarta seção, são apresentados alguns aspectos do projeto Ler + Dá Saúde, ligado ao PNL de Portugal, que visa envolver profissionais de centros de saúde e hospitais com a promoção e associação da leitura à saúde. Embora o foco principal das ações do projeto sejam as crianças de seis meses a seis anos, os profissionais da saúde aconselham a leitura para toda família.

\section{O letramento em leitura}

As alterações sofridas pelas sociedades são refletidas nas diversificadas dinâmicas da vida em coletividade. E, desta forma, as fragmentações sociais, ou eixos de fragmentação social são também alteradas, é o caso da leitura, a qual sofre intervenção na sua própria definição, que vai se alterando a fim de atender as expectativas das demandas atuais.

Assim, em décadas passadas, mais nomeadamente as de 1940 e 1950, a exigência da escolarização consistia apenas em aprender a ler, contar e escrever, haja vista, não ser de interesse dos governantes investir na escolarização da população. Veloso (2005, p.1) aponta que a leitura nessa época era "[... confundida com a mera oralização, redundando numa incapacidade de compreender devidamente o que se lia e de ter o espírito crítico necessário à aquisição do sentido [...]", onde a leitura consistia num ato de decodificar símbolos gráficos, ou seja, "[...] não era mais que o acto de transformar, ou converter, uma sequência gráfica numa sequência fônica e o leitor ser um mero agente passivo". (PROLE, 2005, p. 5) A partir da década de 1970, a leitura é reconhecida como educativa e formativa, e passa a ser uma preocupação de organismos ligados à cultura e ao mundo livreiro (MAGALHÃES, 2009)Contudo, após a década de 1990, a definição do ato de ler começa a ser modificada e um novo modelo é posto, onde a leitura passa da decodificação para a compreensão, que de acordo Sim-Sim e Ramalho (1993), ler é fundamentalmente aceder ao conhecimento por intermédio da construção da informação existente no texto, o que implica uma intima e permanente interação entre o leitor e o texto. Dessa forma, 
o leitor constrói significado e a leitura transforma-se numa grande porta de acesso ao conhecimento. E esta é a base do letramento plena, uma supra capacidade promotora para a transformação social.

A definição de letramento em leitura também é apontada pela Organização para a Cooperação e Desenvolvimento Econômico (OCDE) como sendo a capacidade que cada indivíduo tem de compreender e usar textos escritos e refletir sobre eles, de modo a atingir seus objetivos, a desenvolver seus próprios conhecimentos e potencialidades e participar de forma ativa na sociedade. (PISA, 2001)No atual contexto de grandes transformações políticas, sociais, econômicas e científicas a leitura é requerida como um valor absoluto para qualquer sociedade. Onde a competência funcional da leitura possibilita a aprendizagem de todos os demais conhecimentos os quais são apontados como condições para o sucesso acadêmico, profissional e social do indivíduo.

Neste aspecto, Santa Rosa (2005, p. 1) acrescenta que:

[...] com o desenvolvimento científico e tecnológico que é a característica marcante da sociedade contemporânea, nota-se que a leitura cada vez mais tem se tornado um elemento indispensável para a inserção social do indivíduo e consequentemente para a formação da cidadania, uma vez que através dela ele terá acesso a uma enorme gama de informações e novos conhecimentos que serão de fundamental importância para que possa interagir de uma forma mais consciente na sociedade.

Ademais, a capacidade de ler coloca "[...] à disposição da pessoa a possibilidade de compreender melhor o mundo que a rodeia, bem como de dar respostas às solicitações [...]" (BRANDÃO, 2011, p. 1) impostas pela vida.

\section{As políticas públicas da leitura em Portugal: uma agenda para diversificação}

Nos países da União Europeia (UE), a promoção da leitura tem assumido significativa relevância, que de acordo Ferreira (2009), muitas políticas têm segeneralizado em diversos países, reconhecendo a importância das competências da leitura para o desenvolvimento de cidadãos de pleno direito em sociedades democráticas. 
(2) International Adult Literacy Survey [Pesquisa Internacional de Alfabetização de Adultos]
Contudo, as realidades são distintas entre os países europeus o que leva cada país a apresentar os seus próprios projetos, planos, programas, ações e eventos, com objetivos distintos. Então, cada país da UE atua de acordo com as necessidades da sua população. (FERREIRA, 2009) Neste aspecto, Portugal com base em estudos nacionais (ex. Estudo Nacional de Literacia) e internacionais (ex. PISA, IALS²) se localizava numa situação de desvantagem em letramento em relação aos demais países europeus, conforme destaca Grancho (2013, p. 11), que "[...] há pouco mais de uma década, os vários estudos nacionais e internacionais tornaram evidentes os baixos níveis de literacia dos jovens portugueses, designadamente em leitura, situando-os num patamar significativamente inferior à média europeia."

Com base nos estudos realizados para avaliar o letramento, tanto dos adultos quanto dos estudantes, Pacheco (2012, p. 13) enfatiza que "[...] há, pois, uma consciência generalizada da existência de falta de hábitos de leitura no seio da população portuguesa e, em consequência, de capacidades de ler". Essa deficiência na compreensão leitora, segundo Prole (2005, p. 35) está intrinsecamente "[...] ligada aos hábitos de leitura e o enraizamento da prática leitora requer desde a primeira infância, um contexto estreito e continuado $[\ldots . .]^{\prime}$, e exigente.

\section{O Plano Nacional de Leitura de Portugal}

Nesse contexto, a leitura é posta como uma questão social, e para dar resposta a este problema é lançado em setembro de 2006 através da Resolução do Conselho de Ministros de 12 de julho n. 86/2006, o Plano Nacional de Leitura (PNL). O qual reconhece a relevância da leitura para a formação educativa e social do homem. (GAMBOA, 2012b, p. 1) O PNL foi colocado como prioridade política, e com anseios de ser considerado um desígnio nacional. Conforme enfatizam Neves, Lima e Borges (2007, p. 69):

O PNL constitui uma resposta institucional, coordenada pelo Ministério da Educação, em articulação com o Ministério da Cultura e o Gabinete do Ministro dos Assuntos Parlamentares, à preocupação quanto aos baixos níveis de literacia da população, em particular entre os jovens. Concretiza-se num conjunto de medidas destinadas a promover o desenvolvimento de competências nos domínios da leitura e da escrita, bem 
como o alargamento e aprofundamento dos hábitos de leitura, designadamente entre a população escolar.

O Plano Nacional de Leitura implementado pelo governo português é descrito por Costa e colaboradores (2014) como sendo:

[...] um programa à escala nacional, abrangendo todo o país; actua em diferentes contextos, mais circunscritos, como escolas, bibliotecas e comunidades locais, ou mais difusos, como a sociedade portuguesa em geral; está direccionado para diferentes públicos, incluindo crianças e jovens em idade escolar, adultos, famílias e população em geral; conta com o envolvimento, de formas também variadas, de uma pluralidade de actores, desde a própria Comissão do Plano aos que trabalham directamente com os destinatários no terreno, como sejam os professores, os bibliotecários ou os profissionais de saúde; engloba uma grande quantidade e diversidade de projectos, com diferentes graus de abrangência, objectivos, públicos e durações.

Ainda, conforme os autores supracitados, o plano tem como característica marcante o dinamismo representado pela coexistência dos projetos nucleares desenvolvidos, desde o lançamento do plano a criação e incorporação de novos projetos e iniciativas de promoção à prática leitora (COSTA, et al., 2014).

Através do PNL, o governo de Portugal pretende reduziros baixos níveis de letramento em leitura, desenvolver competências leitoras, despertar o prazer pela leitura e estimular hábitos de leitura apontados como fatores de desenvolvimento social, político, cultural e econômico. Desse modo, a promoção de leitura em Portugal não se esgota no sistema de ensino, embora, seu papel para a formação de leitores seja de grande importância, outros setores assumem também o papel de promover a leitura de ações governativas no nível da cultura, nomeadamente a Rede Nacional de Bibliotecas Públicas (RNBP) e demais setores não públicos.

Em Portugal, o PNL abrange locais diversificados como escolas, bibliotecas, centros de saúde, autarquias e o ambiente familiar, que segundo estudos as competências básicas devem ser adquiridas nas primeiras etapas da vida, assim, Teixeira (2009, p. 33) destaca ser "[...] fundamental despertar o gosto pela leitura através de histórias contadas pelos familiares, pois, assim, conseguem atrair a atenção e o interesse das crianças, estimulando-as para 
a leitura [...]" além disso, a família pode colocar o livro, a leitura e a biblioteca nos hábitos familiares, e assim, a ida à biblioteca poderá ser associada a um momento de lazer. (FRADIQUE, 2011) Ademais, o Plano procura abrigar diversos projetos com variedades de atividades a fim de aproximar o público-alvo aos diversos suportes de leitura, criando o gosto de ler, de modo a formar leitores efetivos, diminuindo assim os níveis de iletrados em longo prazo.

O arranjo dos programas de promoção da leitura consiste em agregar todas as possibilidades para o estimulo à prática leitora, que para Brandão (2011), um plano de ação estruturado, que reúna um conjunto de atitudes coordenadas da biblioteca escolar, da escola e da família, contribui, sem dúvida, para uma mudança significativa de atitudes, principalmente por parte do corpo docente, no que concerne às práticas pedagógicas, e por parte dos alunos, face à motivação e ao desenvolvimento do prazer de ler.

Assim, constitui-se ser de grande importância a participação de toda a sociedade como um espaço educativo, haja vista, a necessidade em formar leitores, tendo em consideração o avanço tecnológico e os novos desafios a que a sociedade atual está submetida diariamente. (FERREIRA, 2009) Então, foram criados projetos de âmbitos e duração diversificados dirigidos aos mais variados contextos sociais, em destaque os desenvolvidos pelas bibliotecas públicas e outros parceiros. (RODRIGUES, 2014) Embora os programas do Plano Nacional de Leitura tenham buscado abranger os mais variados atores sociais, percebe-se a ênfase dada ao público infantil que pelo qual está inserido na maioria dos programas de promoção da leitura, seja através de atividades direcionadas para as crianças, seja nas "[...] ações de sensibilização dos pais para a importância de ler para seus filhos desde muito cedo". (CHERUBINO, 2014, p. 25)

\section{Portal eletrônico do Plano Nacional de Leitura de Portugal}

Com o objetivo de dar agilidade e visibilidade ao Plano, foi desenvolvido um sistema de informação, comunicação e acompanhamento através do portal eletrônico, no qual além de divulgar as ações e projetos do plano, fornece atividades para as ações desenvolvidas e orientações dirigidas à promoção das leituras produzidas. (COSTA et. al., 2014, p. 22) O portal é dirigido tanto aos profissionais que atuam na promoção da leitura, nomeadamente, 
professores, bibliotecários, profissionais de saúde dentre outros, quanto a população de um modo geral e incorpora 12 sítios eletrônicos relacionados aos projetos e as áreas de atuação do Plano. As atividades contidas são organizas por áreas específicas a fim de facilitar e dar celeridade as consultas.

Para Costa e colaboradores (2014, p. 22):

O portal do PNL tem cumprido essencialmente duas funções que se articulam entre si: a função de divulgação e a função de orientação. Por um lado, disponibiliza informação sobre as atividades desenvolvidas não só no âmbito dos projectos do PNL, mas também no quadro de outras entidades, integrando uma base de dados de iniciativas e eventos relacionados com a leitura.

As informações contidas no portal remetem para outros sítios e blogs de escolas com projetos de leitura e para projetos desenvolvidos por outras instituições, de uma certa forma, o portal fornece informações sobre leitura, incluindo eventos, orientações de leitura tanto no contexto escolar como fora dele. Segundo Costa e colaboradores (2014, p. 22), o portal:

[...] disponibiliza ferramentas para a promoção da leitura, atividades essencialmente para as escolas, para as famílias e para profissionais envolvidos, de forma variada, nessa promoção. Estas ferramentas consistem em orientações para a leitura em contexto escolar e em contexto familiar, bem como a elaboração de listas de obras recomendadas.

O portal constitui um importante recurso de gestão, comunicação e informação do PNL ao viabilizar ferramentas tanto para o acompanhamento como para o desenvolvimento de atividades leitoras, para Cherubino (2014, p. 32) "[...] o portal tem como logomarca o termo Ler+, que é uma ferramenta de divulgação que promove o esclarecimento e a aproximação entre o PNL e os utilizadores [...]" desse veículo de comunicação.

As informações disponibilizadas referentes as "[...] atividades desenvolvidas no âmbito do Planoimplicou montar um sistema de informação" (COSTA et al., 2014, p. 24), que permitiu o registro eletrônico das entidades participantes de ações de promoção da leitura, bem como dispor de informações já sistematizadas sobre 
as entidades e os projetos. Essa base possibilita a elaboração de perfis individualizados ou de forma coletiva para a obtenção do perfil de todos os projetos desenvolvidos.

Para Costa e colaboradores (2014, p. 24) o sistema de informação do PNL,

[...] consiste essencialmente num conjunto de bases de dados dinâmicas, geradas pelo registo das instituições nos diversos projectos e actividades do Plano, em formulário electrónico online disponível no Portal do PNL. Entre estas destacam-se: o registo das escolas para o desenvolvimento da leitura orientada em sala de aula e respectivo apoio financeiro para aquisição de livros; o registo de actividades desenvolvidas pelas escolas durante a Semana da Leitura; a inscrição das unidades de saúde no projecto Ler+ dá Saúde; o registo dos CNO no projecto Novas Oportunidades a Ler; e o registo do Plano de Desenvolvimento da Promoção de Leitura das autarquias com quem o PNL estabeleceu protocolos.

A proposta do Plano Nacional de Leitura é de uma política inclusiva e facilitadora de oportunidades, nomeadamente de ascensão social e econômica, além de possibilitar a consciência cidadã, que de acordo o segundo relatório de atividades da segunda fase do PNL (2013), o plano tem estabelecido parcerias com o objetivo de alargar a rede de organizações dos setores público e privado, bem como a sociedade civil que contribui para a criação de um ambiente social mais favorável para a expansão de hábitos culturais na área do livro e da leitura.

Nessa perspectiva, e a fim de ampliar os ambientes, os atores e as possibilidades que a leitura possa vir a oportunizar, o Plano Nacional de Leitura lança o Projecto Ler+ Dá Saúde, o qual aposta na influência positiva que os profissionais de saúde podem ter no desenvolvimento do letramento das crianças.

\section{Ler Mais Dá Saúde!: alguns aspectos do projeto}

O Plano Nacional de Leitura criou o Projeto Ler + Dá Saúde, com o propósito de envolver os profissionais do centro de saúde e dos hospitais na orientação da leitura em família, que, segundo apresentado pelo Plano, 
Uma população menos escolarizada e com nível de literacia fraco, apresenta maior resistência à mudanças de estilos de vida, menor entendimento e adesão aos conselhos médicos, menor cumprimento da terapêutica, menor capacidade de gestão das suas doenças crônicas, maior taxa de hospitalização e uso inadequado dos serviços de saúde. (PNL, 2006, p. 6)

Desta forma, o Projeto Ler + Dá Saúde foi desenvolvido com vistas a promover o letramento precoce, estimulando práticas de leitura partilhada em família, em especial com crianças entre seis meses a seis anos de idade, uma vez que "[...] para evitar problemas na aprendizagem da leitura é aconselhável a intervenção precoce da família, logo a partir dos 6 meses de idade". (PNL, 2006, p. 8) Para fins de ilustração, segue a Figura 1.

Figura 1: Portal Ler + Dá Saúde

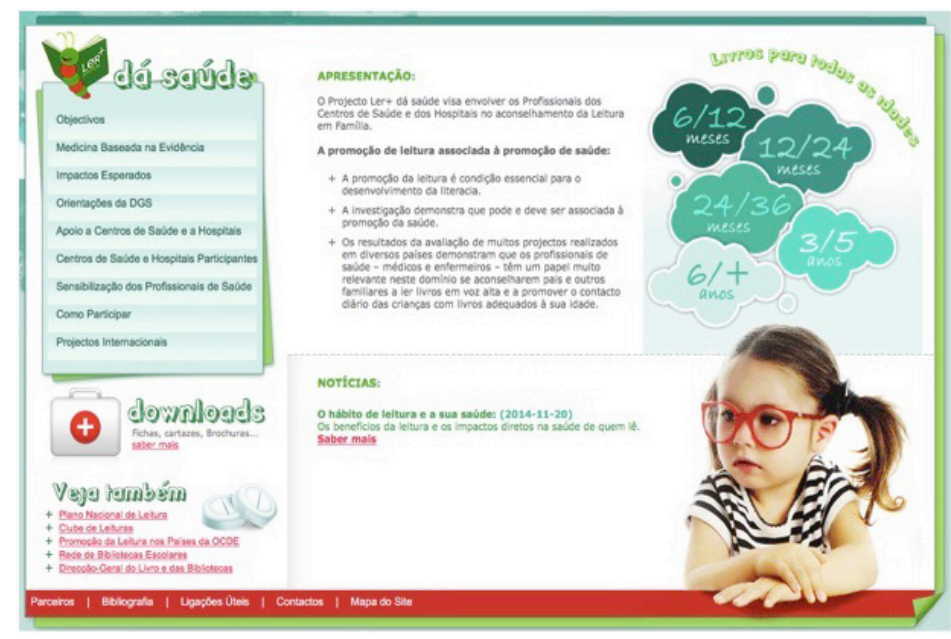

Fonte: Governo de Portugal (2017). ${ }^{3}$

Como é possível perceber a Figura 1, o portal Ler + Dá Saúde une leituras direcionadas para cada faixa etária, dentro do grupo etário estabelecido pelo projeto, com informações médicas básicas e de instituições de saúde. O projeto procura ainda sensibilizar famílias portuguesas para o valor da leitura em ceio familiar, recorrendo ao aconselhamento dos profissionais de saúde. E por fim, deve-se também considerar como objetivo do projeto contribuir para as orientações estratégicas do Plano Nacional de Saúde (3) http://www. planonacionaldeleitura.gov.pt/ arquivo/lermaisdasaude/ 2004-2010, em destaque no que se refere ao aumento do nível de saúde nas diferentes fases do ciclo de vida. 
O projeto ainda aponta que,

Os baixos índices de literacia têm consequências directas na saúde: acesso mais limitado a informação relativa à saúde; uso incorreto dos serviços de saúde e dos medicamentos; dificuldade em cumprir as prescrições médicas; Erros na administração de medicamentos às crianças; maior risco de acidentes domésticos, no trabalho, nos transportes; menor adesão aos programas de rastreio e profilaxia; estilos de vida menos saudáveis. (PNL, 2006, p. 9)

No entendimento do Plano, esse projeto viabiliza a participação dos cidadãos na criação de contextos ambientais conducentes à saúde, por meio do desenvolvimento do letramento e do estimulo à leitura, visando potencializar o conhecimento dos cidadãos.

Nesse contexto, as ações são desenvolvidas através de leitura diária de livros em voz alta nas consultas médicas e na observação das crianças feita por médicos e enfermeiros a fim de promover o contato precoce com livros. Conforme ilustrado na Figura 2.

Figura 2: Folheto de Divulgação e Sensibilização dos Profissionais de Saúde

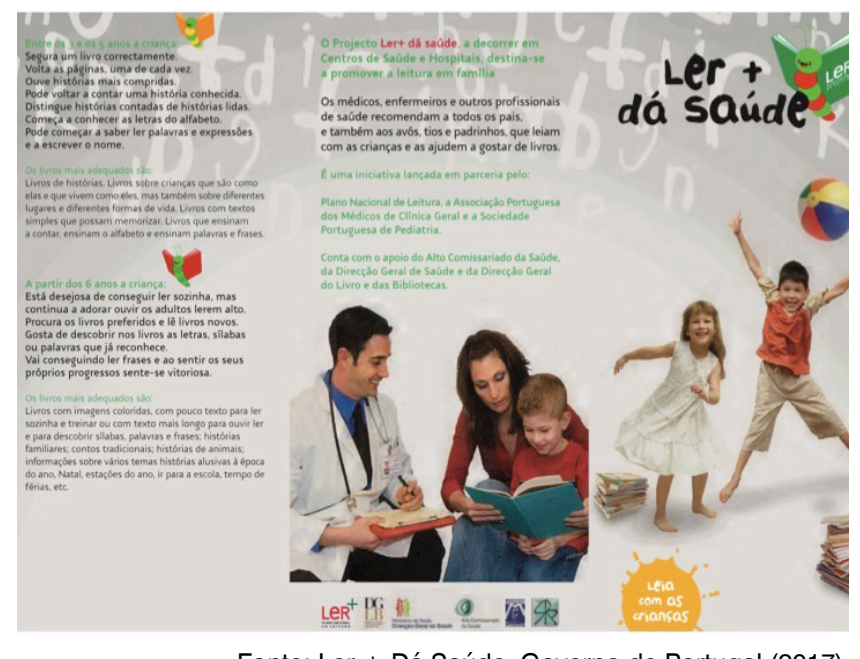

Fonte: Ler + Dá Saúde. Governo de Portugal (2017).

O folheto chama atenção à existência de interesse em sensibilizar os profissionais da área de saúde para a importância do projeto, conforme descrito na Figura 2. De acordo com Bonfim e colaboradores (2012), também no Brasil, existem ações que visam estímulos a leitura com o apoio dos profissionais de leitura 
identificados e desenvolvidos pela equipe do Programa de Agentes Comunitários de Saúde (PACS) criado pelo Ministério da Saúde, em 1997. São desenvolvidas nestas ações: caminhadas, grupo de leitura com crianças, campanhas de hipertensão e diabetes, grupo de fuxico, reunião de quarteirão, dentre outras.

Tanto o PACS como Estratégia Saúde da Família (ESF) são formas de organizar a Atenção Básica e têm por finalidade a mudança do modelo assistencial em curso, que se caracteriza por ser um modo de organizar serviços e produzir ações de saúde centrado em procedimentos, fragmentado, biologicista e medicalizante. (BONFIM, et al., 2012) Contudo, o programa e suas respectivas ações não seguem diretrizes ou tem quaisquer ligação com o Plano Nacional de Leitura brasileiro.

Em Portugal, tal ação de incentivo à leitura busca aumentar a capacidade de aprendizagem, elevar os níveis de letramento infantil e de oportunizar o sucesso acadêmico futuro. Com a elevação da escolaridade e do letramento em adultos, acredita-se na elevação da probabilidade de sucesso pessoal. Uma vez que, o aumento do letramento em saúde aumenta a capacidade de escolha de estilo de vida saudáveis, aumentando também a capacidade de compreensão das mensagens em saúde e o cumprimento das orientações dos profissionais de saúde.As ações de leitura visam ainda melhorar a capacidade de gerir doenças crônicas e diminuir a probabilidade de hospitalização além de aumentar o tempo de sobrevida.O projeto tem como parceiros:

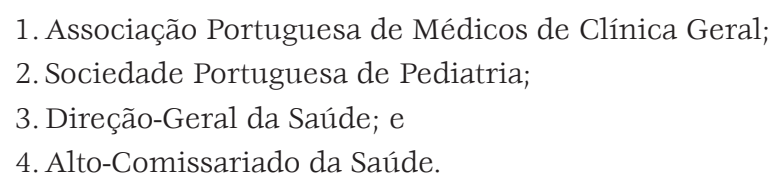

Espera-se a partir deste projeto de estímulo à leitura, que a criança ampliea capacidade de expressão e de compreensão verbal, que resultará numa melhor preparação para a aprendizagem formal do letramento, bem como modificar a atitude dos pais e responsáveis em relação à leitura em família.

E por fim, através deste projeto, busca-se o uso e acesso a serviços de saúde através de uma melhor compreensão de fatores indutores de saúde e de doença na criança e no adulto, como também a promoção de comportamentos de prevenção de riscos. 


\section{Considerações finais}

De acordo com o apresentado, infere-se que a formação de leitores não pode mais ser circunscritas como exclusividade das bibliotecas e das escolas, nomeadamente dos bibliotecários e professores de língua portuguesa e sim implica no envolvimento de todos os agentes educativos, da família e da sociedade.

Bem como a utilização de todos os recursos disponíveis dos tradicionais aos ofertados pelas TIC, pois só assim a leitura poderá se tornar numa atividade suficientemente aliciante para despertar o interesse e a participação das crianças e dos jovens. Haja vista, ser o letramentouma exigência da sociedade atual e, portanto, indispensável para o sucesso individual, escolar e profissional, como condição fundamental para o pleno exercício da cidadania.

O estímulo da leitura para o desenvolvimento do letramento, desta forma, tem sido associada à promoção da saúde por meio do Plano Nacional de Leitura português.

Os resultados das observações e discussões, com a literatura sobre o tema proposto, permitiram concluir que o PNL tem se destacado comoproposiçãosocial por ser uma política pública que tem visado a convergência da leitura, com a saúde e o envolvimento da família. O projeto Ler + Dá Saúde, desenvolvido no contexto do PNL, une ainda a preocupação com a sensibilização dos profissionais da Saúde, disponibilizando roteiros ilustrativos e informativos baseados em estratégias para orientar a leitura, das crianças em atendimento, pelos pais e familiares.

Pode-se destacar o uso dado às TIC para divulgação e recurso de interação com os profissionais da Saúde e familiares. Aspecto este que tem sido reconhecido como proposta estratégica do programa PNL para fortalecer o letramento no país.

Vale salientar que as observações realizadas nos documentos e nos sítios eletrônicos ligados ao Programa, assim como a bibliografia para desenvolver as análises, suscitaram os seguintes questionamentos para estudos futuros: como os profissionais da saúde daquele país têm interagido com as famílias por meio das propostas de leitura indicadas pelo Projeto? Como o projeto, enquanto ação de uma política pública tem sido avaliado? Existem dados que comprovem correspondência entre o estímulo a leitura e o aumento do nível de saúde entre as amostras de crianças atendidas-beneficiadas pelo projeto? 
Assim, conforme o apresentado no texto é salutar a importância das políticas públicas de leitura quando voltadas para as demandas de letramentos de uma determinada sociedade. E acredita-se que os profissionais de saúde têm um importante papel no domínio de aconselhamento aos pais e responsáveis das crianças a lerem livros em voz alta e na promoção do contato diário das crianças com os livros.

\title{
Public policies and health promotion through reading: read + give health!
}

\begin{abstract}
The objective of this article is to present a brief review of the field of studies that articulates public policies and health promotion through reading. The theme is the public policy for reading and the object is the project Ler + DáSaúde developed by the National Reading Plan of Portugal (NRP). Its specific objectives are to demonstrate the importance of literacy in reading, to discuss some of the public policies in Portugal, and to highlight some aspects of the Ler + DáSaúde project. As a methodology, it is a revision text, and thus constitutes the type Bibliographical and documentary. Portal data and electronic NRP siteswere used, such as Ler + DáSaúde (Read + Gives Health). The results of the observations and discussions with the literature on the proposed theme allowed to conclude that the project has stood out as a social proposal because it is a public policy that has aimed at the convergence of reading, health and family, joining information and communication technologies). And as a strategic proposal of the NRP program to strengthen literacy in the country.
\end{abstract}

Keywords: Public reading policies. National Reading Plan. Portugal. Ler + DáSaúde. Project. HealthPromotion.

\section{Referências}

BONFIM, P. F. et. al. Ações educativas em um Programa de Agentes Comunitários de Saúde.Revista Brasileira de Enfermagem, Brasília, v. 65, n. 3, p. 420-427, jun. 2014. Disponível em:< http://www.scielo.br/ scielo.php?script $=$ sci_arttextEpid $=$ S0034-71672012000300005Elng $=$ en $\Xi \mathrm{nrm}=$ iso > . Acesso em: 11 jun. 2017.

BRANDÃO, O. F. R. A Ler + em Mitheirós de Poiares: um projecto em acção. 2011. Dissertação (Mestrado em Gestão da Informação e Bibliotecas Escolares) - Universidade Aberta, Lisboa, 2011.

CHERUBINO, I. M. P. Políticas públicas de leitura: estudo comparativo dos Planos Nacionais de Leitura de Portugal e do Brasil (Dissertação de Mestrado) - Faculdade de Ciências Sociais e Humanas, Universidade Nova de Lisboa, Lisboa, 2014.

COSTA, E. et al. O 'Programme for International Student Assessment' (PISA) como instrumento de regulação. Disponível em: < http:// repositorio.ul.pt/handle/10451/3002 >. Acesso em: 4 jul. 2014. 
FERREIRA, S. C. T. O Plano Nacional de Leitura e a promoção de hábitos de leitura nas escolas do $1^{\circ}$ ciclo do ensino básico: um estudo de caso.

2009. Dissertação (Mestrado em Educação) - Departamento de Ciências da Educação e do Patrimônio, Universidade Portucalense Infante D. Henrique, Porto, Portugal, 2009.

FRADIQUE, M. F. S. C. As bibliotecas escolares e o papel do professor bibliotecário. 2011. Dissertação (Mestrado em Ciências Documentais) Universidade da Beira Interior, Covilhã, 2011.

GAMBOA, M. J. Possibilidades e pontos de resistência na recepção do Plano Nacional de Leitura - Para uma análise de prácticas de leitura. Exedra: Revista Científica, n. 6, p. 129-138, 2012.

GRANCHO, J. Ler + Plano Nacional de Leitura: Relatório de atividades 2012 - 2013 ( $2^{\text {a }}$ fase $-2^{\circ}$ ano), Lisboa: Ministério da Educação, Portugal, 2013.

MAGALHÃES, J.Education, lecture et langagedanslasociété de laconnaissance, de l'information et de la communication. In: GONÇALVES, C.; GROUX, D. (Coord.). Approches comparées de l'enseignementdes langues et de la formation desenseignants de langues. Paris: L'Harmattan, 2009. p. 49-56. Disponível em: < http://repositorio. ul.pt/bitstream/10451/5011/1/Educa\% C3\%A7\%C3\%A3o\%2c\%20 leitura\%20e\%20linguagem.pdf > . Acesso em: 21 ago. 2015.

NEVES, J. S.;LIMA, M. J.;BORGES, V. Prácticas de promoção da leitura nos países da OCDE. Lisboa: Gabinete de estatística e Planeamento da Educação. Ministério da Educação, 2007.

PACHECO, C. M. G. M. O Plano Nacional de Leitura nos media: uma análise de representações. 2012. Dissertação (Mestradoem Ciências da Educação) - Instituto de Educação, Universidade do Minho, Braga, 2012.

PISA. Conhecimento e atitudes para a vida: Resultados do PISA 2000 - Programa Internacional de Avaliação de estudantes/OCDE. Organização para a cooperação e desenvolvimento econômicos. São Paulo: Moderna, 2001.

PLANO NACIONAL DE LEITURA. Portugal. Resolução do Conselho de Ministros de 12 de julho n. 86/2006. Aprova o Plano Nacional de Leitura e cria sua respectiva comissão. Diário da República, $1^{\text {a }}$ série, n. 133, 2006.

PLANO NACIONAL DE LEITURA. Relatório de atividades 2012-2013, $2^{\text {a }}$ fase, $2^{\circ}$ ano, 2013. Disponível em: < http://www. planonacionaldeleitura.gov.pt/arquivo/pnltv/uploads/balancos/ relatorio_do_2_ano_2_fase_a.pdf >. Acesso em: 11 ago. 2017.

PROLE, A. O papel das bibliotecas públicas face ao conceito de literacia. In. Seminário Educação e leitura: Actas 27/28 de Outubro de 2005. 
Esposende: Câmara Municipal, Portugal, 2005, 31-41p. Disponível em: < http://biblioteca.esec.pt/Opac/Pages/Document/DocumentCitation. aspx?UID = f5e83004-6578-4d29-9ad4-940d66250845\& DataBase $=10200$ GLOBAL > Acesso em: 15 maio 2017

RODRIGUES, M. L. (Org.). 40 anos de políticas de educação em Portugat: volume II conhecimento, atores e recursos. Coimbra: Almedina, 2014, 620 .

SANTA ROSA, C. S. de. Leitura: uma porta aberta na formação do cidadão, 2005. Disponível em: <http://portal.educacao.salvador.ba.gov. br/site/documentos/espaco-virtual/espaco-autorias/artigos/leitura\%20 -\%20uma\%20porta\%20aberta...pdf>. Acesso em: 20 Nov. 2016.

SIM-SIM. I.; RAMALHO, G. Como leem as nossas crianças? Caracterização do nível de literacia da população escolar portuguesa. Lisboa: Me-Gep, 1993.

TEIXEIRA, J. B. Formulação, administração e execução de políticas públicas. In: Serviço Social: direitos sociais e competências profissionais. Brasília, DF: CFESS/ABEPSS, 2009. Disponível em: < http://www. cressrn.org.br/files/arquivos/5x595ziU0wuEf5yA63Zw.pdf $>$. Acesso em: 14 abr. 2017.

VELOSO, A. A leitura literária. In: SEMINÁRIO EDUCAÇÃO E LEITURA. 2005, Esposende. Actas... Câmara Municipal, 23-29p. Disponível em: <http://biblioteca.esec.pt/Opac/Pages/ Document/DocumentCitation.aspx?UID = 4dd9100f-ef77-4fc4-8d747fe33037fca2\&DataBase=10200_GLOBAL>. Acesso em: 15 maio 2017 
